\title{
Characterization of the Multiple-Copy Host-Selective Toxin Gene, ToxB, in Pathogenic and Nonpathogenic Isolates of Pyrenophora tritici-repentis
}

\author{
J. Patrick Martinez, Nicholas W. Oesch, and Lynda M. Ciuffetti \\ Dept. of Botany and Plant Pathology, Oregon State University, Corvallis, OR 97331, U.S.A. \\ Submitted 3 October 2003. Accepted 29 November 2003.
}

ToxB, a gene that encodes a 6.6-kDa host-selective toxin (HST), is present in several races of the wheat pathogen Pyrenophora tritici-repentis. To learn more about the multiple ToxB open reading frames (ORFs), six of the estimated nine copies from a race 5 isolate were cloned and analyzed. All six copies of ToxB have identical 261-bp ORFs and thus encode the same form of Ptr ToxB. Sequence analysis of regions flanking the cloned ToxB loci revealed that the majority of loci are associated with portions of retrotransposons and a transposon-like sequence. Data indicate that ToxB loci reside on two chromosomes, 3.5 and $2.7 \mathrm{Mb}$, with the majority of copies located on the $2.7 \mathrm{Mb}$ chromosome. A related gene, referred to as toxb, from a nonpathogenic race 4 isolate was also cloned and characterized. This is interesting because, until now, HST genes have only been found in toxin-producing, pathogenic isolates of plant pathogenic fungi. The toxb gene from nonpathogenic isolates is $86 \%$ similar to ToxB, and data suggest that toxb is a single-copy gene. No toxb transcript was detected under culture conditions that favor the expression of ToxB; therefore, these genes differ in their transcriptional regulation.

Additional keywords: multicopy gene, pathogenicity factor, tan spot.

The fungus Pyrenophora tritici-repentis (Died.) Drechs., causal agent of tan spot of wheat, causes significant economic losses in major wheat-growing areas throughout the world. Eight races have been described, based on lesion phenotype on four differential wheat lines (Lamari et al. 1995, 2003; Strelkov et al. 2002). Additional races have been identified, but they have not yet been fully characterized (Ali and Francl 2002; Ali et al. 2003; Manning et al. 2002). Development of disease symptoms from $P$. tritici-repentis involves the production of one to several host-selective toxins (HST) (Ciuffetti and Tuori 1999; DeWolf and Francl 1998; Lamari et al. 2003; Wolpert et al. 2002). The proteinaceous HST Ptr ToxA (Ballance et al. 1989; Tomas et al. 1990; Tuori et al. 1995; Zhang et al. 1997) [syn. Ptr necrosis toxin, Ptr Toxin, and ToxA (Ciuffetti et al. 1998)] was the first toxin to be fully characterized in $P$. tritici-repentis. The singlecopy gene, ToxA, encodes the toxin Ptr ToxA, which is present in several races of the tan spot fungus (Ballance et al. 1996; Ciuffetti and Tuori 1996; Ciuffetti et al. 1997). Transformation

Corresponding author: L. M. Ciuffetti

E-mail: ciuffetL@science.oregonstate.edu

Current address of N. W. Oesch: Department of Neurological Sciences Institute, Oregon Health Sciences University, Beaverton, OR 97006, U.S.A. of a nonpathogenic isolate with the ToxA gene demonstrated that Ptr ToxA functions as a pathogenicity factor in the Pyrenophora-wheat interaction (Ciuffetti et al. 1997).

Ptr ToxB (syn. Ptr chlorosis toxin) was the second HST to be characterized in $P$. tritici-repentis (Strelkov et al. 1999). Like Ptr ToxA, Ptr ToxB is a protein toxin. Additional HST have been identified and partially characterized from $P$. triticirepentis, including Ptr ToxC (Effertz et al. 2002) and Ptr ToxD (Ali et al. 2002; Manning et al. 2002). It should be noted that preliminary reports by Ali and associates (2002) and Manning and associates (2002) describe two chemically distinct HST that currently share the same name, Ptr ToxD. Race 5 isolates of $P$. tritici-repentis, first found in Algeria, are characterized by the production of lesions with spreading chlorosis on wheat cultivar Katepwa (Orolaza et al. 1995). Race 5 isolates were later identified in North Dakota (Ali et al. 1999). This hostselective chlorosis has been attributed to a 6.6-kDa HST, Ptr ToxB (Martinez et al. 2001a; Strelkov et al. 1999). Ptr ToxB is encoded by a multiple-copy gene, ToxB, comprising a 261-bp open reading frame (ORF) (Martinez et al. 2001a). ToxB has recently been found in races 6,7 , and 8 , which are all pathogenic on the cultivar Katepwa (Lamari et al. 2003; Strelkov et al. 2002).

Six ToxB loci from a race 5 isolate were cloned and characterized to determine if they encode variants of the chlorosis toxin, Ptr ToxB. Additional sequences from the flanking regions of the six loci were analyzed for clues about the evolution of this multicopy gene. A ToxB related gene, toxb, was found in nonpathogenic isolates (Martinez et al. 2001b, 2002). This is interesting because, until now, HST genes have been found exclusively in pathogenic isolates with no corresponding allele or locus in nonpathogenic isolates. To investigate the significance of a toxin-related gene in nonpathogenic isolates, we cloned the toxb gene and compared its expression to that of Tox $B$ in culture. The chromosomal organization of ToxB and toxb were also determined by Southern analysis of chromosomes resolved by clamped homogenous electric field (CHEF)pulsed field gel electrophoresis.

\section{RESULTS}

Southern analysis of $\operatorname{Tox} B$ in various races of $P$. tritici-repentis.

Five genomic HindIII fragments from race 5 isolates of $P$. tritici-repentis hybridized to the ToxB probe (Fig. 1A). Because HindIII does not cut within the 186-bp probe, this result suggests there could be at least five ToxB loci in race 5 isolates. However, not all of the HindIII fragments hybridized with equal intensity. Assuming that the 1.7-kb band represents 
a single ToxB locus, phosphorimage analysis of band intensity relative to the $1.7-\mathrm{kb}$ band indicates that there are nine ToxB loci in the race 5 isolates (data not shown). Races 1, 2, 4, and 9 (Manning et al. 2002), known not to produce Ptr ToxB, were also screened for the presence of ToxB or a ToxB-related sequence. When Southern blots were washed at low stringency, a single band was detected in the race 4 isolate, and no bands were detected in races 1,2 , or 9 (Fig. 1A). When blots were washed at high stringency, the race 4 band becomes very faint relative to the bands in the race 5 isolates (data not shown), thus indicating that the single band in race 4 isolates only shares partial homology to the ToxB probe. Consequently, the ToxB locus in nonpathogenic race 4 isolates is referred to as toxb.

\section{Sequence analysis of the multiple-copy $T o x B$ gene from pathogenic race 5 isolates and the related toxb gene from nonpathogenic race 4 isolates.}

To learn more about the multiple ToxB loci and the toxb locus, six ToxB loci and the toxb locus were cloned and sequenced. Analysis of the six ToxB loci revealed that all six loci have identical To $x B$ ORFs and, thus, encode the same form of Ptr ToxB. Phosphorimage analysis of band intensity of the Southern blot shown in Figure 1 suggested that there are three to four copies of ToxB in the 2.86-kb HindIII fragment. Two of the 2.86-kb ToxB loci, ToxB1 and ToxB2, were cloned. The
HindIII fragments that contain ToxB1 and ToxB2 are exactly the same size but differ by a 162-bp inversion (Fig. 1B).

As a result of our cloning strategy, the ToxB HindIII clones contain only $270 \mathrm{bp}$ of sequence upstream of the ToxB ORF, whereas these same clones contain an average of $1,400 \mathrm{bp}$ downstream of the ORF. Analysis of sequence downstream of the ToxB ORFs indicated that four of the loci contain coding sequence with significant similarity to known proteins. The two $2.86-\mathrm{kb}$ loci (ToxB1 and ToxB2) and the 2.61-kb locus (ToxB3) had a 267-bp region with similarity to a fungal geranylgeranyl pyrophosphate synthetase (accession number $\mathrm{P} 24322$, E value $\left.=5 \times 10^{-15}\right)$. The $2.86-\mathrm{kb}$ loci contained an additional ORF of $432 \mathrm{bp}$. When the protein databases were searched with this ORF, 321 of the $432 \mathrm{bp}$ had similarity to a reverse transcriptase found in retrotransposons (accession number AF018033, E value = 0.018) (Fig. 1B, red line). A 400-bp region of the 1.7-kb locus (ToxB4) also showed similarity to various plant retrotransposons (accession number AAK02020, E value = 0.004) (Fig. 1B, red line).

To learn more about sequence upstream of the ToxB ORFs, a combination of thermal asymmetric interlaced-polymerase chain reaction (TAIL-PCR) and PCR with locus-specific primers was employed (Table 1). Analysis of the 5' flanking sequences revealed that at least five of the six ToxB loci have a retrotransposon sequence upstream of the ORF (Fig. 1B, red line). This 288-bp retrotransposon-like sequence was most similar to the

\section{A

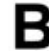

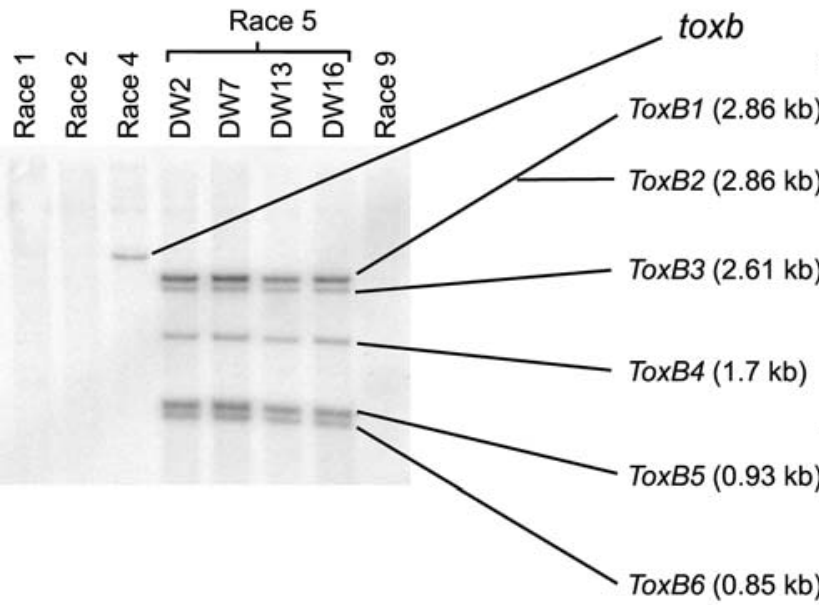

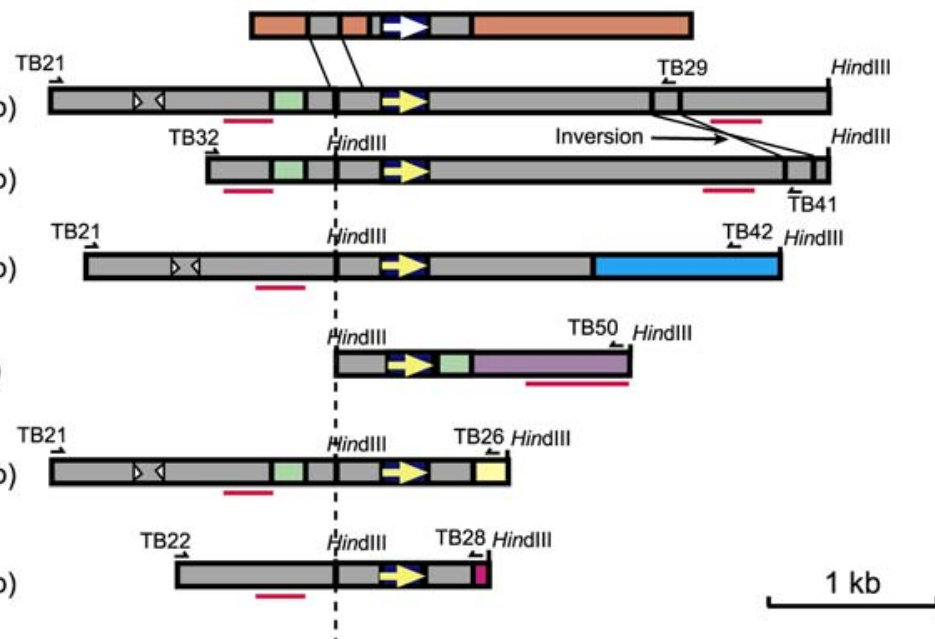

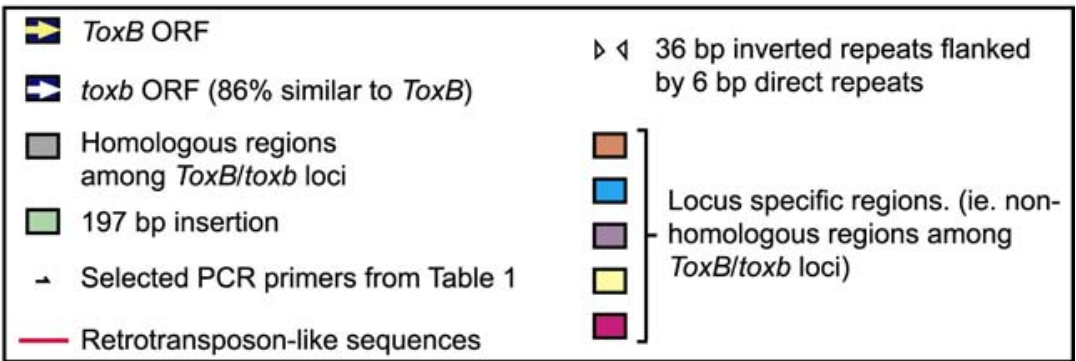

Fig. 1. Pathogenic race 5 isolates of Pyrenophora tritici-repentis have multiple copies of ToxB and race 4 isolates, which are nonpathogenic, have a single copy of a related gene (toxb). A, HindIII-digested genomic DNA of various races of $P$. tritici-repentis was hybridized with a ToxB probe. Blots were washed at low stringency to detect toxb (race 4), which is $86 \%$ similar to ToxB. B, Diagram of six ToxB loci, the toxb locus, and their flanking DNA sequences. For the ToxB loci, sequence to the right of the dotted line represents data from ToxB clones from HindIII genomic libraries, except the 1.7-kb locus (ToxB4) was cloned by inverse-polymerase chain reaction (I-PCR) of HindIII-digested genomic DNA. The size of the HindIII clone is indicated next to the locus name. Sequence to the left of the dotted line was obtained by thermal asymmetric interlaced-polymerase chain reaction and PCR with locus-specific primers. Sequence for toxb is listed under GenBank accession number AY083456. The accession numbers for the ToxB loci and their flanking regions are: ToxB1, AY425480; ToxB2, AY425481; ToxB3, AY425482; ToxB4, AY425483; ToxB5, AY425484; and ToxB6, AY425485. 
gypsy-like retrotransposon, Maggy, from Magnaporthe grisea (accession number AAA33420, E value $=2 \times 10^{-5}$ ). The sequence of the $5^{\prime}$ flanking region for the 1.7-kb locus (ToxB4) was not determined, because efforts to obtain additional $5^{\prime}$ sequence for this locus using TAIL-PCR and inverse (I)-PCR were unsuccessful. At least three of the loci have what appears to be a truncated transposon; that is, 36-bp inverted repeats flanked by 6-bp direct repeats (Fig. 1B, opposing arrowheads). Also, a 197-bp insertion is present upstream of the ToxB ORF in the 2.86- (ToxB1, ToxB2) and 0.93-kb (ToxB5) loci. In contrast, this same 197-bp sequence is located downstream of the ORF for the 1.7-kb locus (ToxB4) (Fig. 1B, green box).

The toxb ORF is $86 \%$ similar to ToxB, and the predicted protein Ptr toxb is one amino acid longer than Ptr ToxB and shares $81 \%$ identity to Ptr ToxB (Fig. 2). Some DNA sequence flanking the toxb ORF is also found in most of the ToxB loci, but overall, a significant proportion of the toxb-flanking sequence is unique to toxb (Fig. $1 \mathrm{~B}$, orange regions). Most notable are sequence differences upstream of the ToxB and toxb ORFs that are expected to be within the promoter and enhancer regions. Based on our previous analysis of ToxB (Martinez et al. 2001a) in conjunction with partial amino acid sequence of secreted Ptr ToxB (Strelkov et al. 1999) and predictions made by the signal peptide prediction program SignalP version 1.1 (Nielsen et al. 1997), it is clear that the first 23 amino acids of Ptr ToxB encode a signal peptide. Likewise, SignalP version 1.1 predicts that $\mathrm{Ptr}$ toxb has a 23 -amino acid signal peptide (Fig. 2). Similar to Ptr ToxB, Ptr toxb has no significant similarity to described proteins in the NCBI databases or to conserved protein motifs in the PROSITE database (Sigrist et al. 2002).

Experiments with toxb-specific PCR primers confirmed that toxb is absent from race 5 isolate DW7, and similar experiments with $T o x B$-specific primers confirmed that ToxB is absent from race 4 isolate SD20 (data not shown).

\section{Chromosome location of the ToxB loci and the toxb locus.}

To determine the genetic organization of the ToxB loci and the toxb locus at the chromosomal level, chromosomes of race 5 isolate DW7 and nonpathogenic race 4 isolates SD20 and 9831-2 were resolved on CHEF gels and were analyzed by Southern blot hybridization. When these blots were probed simultaneously with ToxB and toxb, two prominent bands, 3.5 and 2.7 $\mathrm{Mb}$, were detected in pathogenic isolate DW7 along with several weakly hybridizing bands (Fig. 3B and D). In Figure 3C and $\mathrm{D}$, the $3.5-\mathrm{Mb}$ chromosome comigrates with the $3.1-\mathrm{Mb}$ chromosome, because electrophoretic conditions (method II) used for this gel and the corresponding blot were designed to resolve chromosomes around $2.7 \mathrm{Mb}$. As expected, only a single band was detected in nonpathogenic isolates SD20 (3.2 Mb) and 98-31-2 (3.1 Mb) (Fig. 3B). In isolate DW7, the 2.7-Mb band is more intense than the $3.5-\mathrm{Mb}$ band, suggesting that most of the To $x B$ copies are located within the 2.7-Mb band (Fig. 3B and D). Based on a comparison of band intensity of the stained $\mathrm{CHEF}$ gel shown in Figure 3A, the 2.7-Mb band appears to represent more than one chromosome. However, a different set of CHEF conditions (method II), designed to better resolve the 2.7-Mb chromosome, suggests that the 2.7-Mb band in DW7 represents a single chromosome (Fig. 3C). Chromosome bands in DW7 other than the 3.5- and 2.7-Mb bands also appear to hybridize to the ToxB/toxb probes when blots were washed at high stringency. These may represent truncated ToxB sequences. This interpretation is based on comparisons of staining intensity (Fig. 3A) and phosphorimage intensity (Fig. 3B) of the 3.2-Mb toxb-containing chromosome in the nonpathogenic race 4 isolate SD20 with the staining intensity and phosphorimage intensity of the weakly hybridizing chromosomes of isolate DW7. The intensity of the toxb-containing chromosome in SD20 is expected to be from a single gene copy, and thus, the weakly hybridizing chromosomes in DW7 are less intense than expected for a single copy. No additional chromosomes of isolate DW7 larger than those shown in Figure 3A were resolved under conditions (method III) that resolved chromosomes up to about 4.6 Mb (data not shown). Method III electrophoretic conditions were used to estimate the size of the $3.5-\mathrm{Mb}$ chromosome in isolate DW7.

\section{Expression analysis of ToxB and toxb.}

To examine mRNA expression levels of ToxB and toxb, isolates DW7 (ToxB) and SD20 (toxb) were grown in modified Fries medium for 5, 10, and 15 days with constant illumination. DW7 is typically grown under these conditions in our lab for 15 to 18 days for the production of Ptr ToxB. Based on

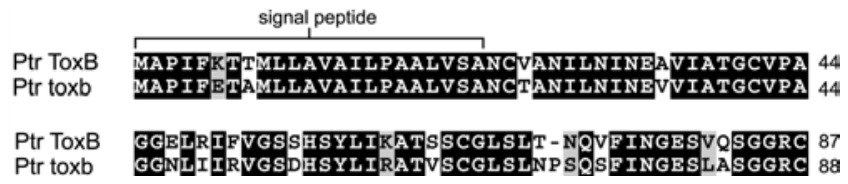

Fig. 2. Alignment of Ptr ToxB and Ptr toxb from Pyrenophora triticirepentis. 'BLAST 2 Sequences' (Tatiana et al. 1999) was used to align the protein sequences. Identical amino acids are highlighted with black and conserved amino acids are highlighted with gray. The sequence for Ptr ToxB (GenBank accession number AY007692) was published previously (Martinez et al. 2001a). Sequence data for Ptr toxb are listed under GenBank accession number AY083456.

Table 1. Primers used to obtain additional sequence 5' of the 6 HindIII ToxB clones.

\begin{tabular}{|c|c|c|}
\hline Primer & Sequence (5' to 3 ') & Comments \\
\hline TB3 & CTTGATTAGTAAGGCTGAGACCACAGG & $\begin{array}{l}\text { Reverse primer for ToxB thermal asymmetric interlaced-polymerase chain } \\
\text { reaction (TAIL-PCR) }\end{array}$ \\
\hline TB5 $^{\mathrm{a}}$ & CTACCCACGAATATGCGAAGCTCC & Reverse primer for ToxB TAIL-PCR \\
\hline TB6 $^{\mathrm{a}}$ & ACGTCCTCCACTTTGCACACTCTC & Reverse primer for ToxB TAIL-PCR \\
\hline TB21 & ATGAATCCGGGCATGAGGTG & Forward primer for assigning 5 ' region to $T o x B$ loci \\
\hline TB22 & GCTATCGCCTAAGTTGCACC & Forward primer for assigning 5 ' region to $T o x B$ loci \\
\hline TB26 & TCTCCATCCTTCTGCCCTTC & Reverse primer specific for ToxB5 \\
\hline TB28 & TAACCCAACCCCAACCACAC & Reverse primer specific for ToxB6 \\
\hline TB29 & TAGACTCCGCAACAATCAATTC & $\begin{array}{l}\text { Part of inverted region between } T o x B 1 \text { and } T o x B 2 \text {; used as a reverse locus- } \\
\text { specific primer for ToxB } 1\end{array}$ \\
\hline TB32 & GGAAGCCCCTAGTTAAGACC & Forward primer for assigning 5 region to $T o x B$ loci \\
\hline TB41 & TCCGCAACAATCAATTAAGTG & $\begin{array}{l}\text { Part of inverted region between } T o x B 1 \text { and } T o x B 2 \text {; used as a reverse locus- } \\
\text { specific primer for ToxB2 }\end{array}$ \\
\hline TB42 & СССТTТСССТTCAGCTTC & Reverse primer specific for $T o x B 3$ \\
\hline TB50 & ACCTCGCTACAGCAAAGC & Reverse primer specific for ToxB 4 \\
\hline TP1 & NGTCGASWGANAWGAA & TAIL-PCR primer used to clone sequence 5 ' of ToxB ORF \\
\hline
\end{tabular}

${ }^{\text {a }}$ Primers also used for applications other than obtaining additional sequence 5 ' of the ToxB clones. 
Northern blot analysis of total RNA, it appears that toxb is not expressed under culture conditions that favor the expression of ToxB (Fig. 4A). However, very low transcript levels often cannot be detected with Northern analysis of total RNA. To maximize detection of rare toxb transcripts, we performed reverse-transcriptase (RT)-PCR with platinum $\mathrm{Taq}$ polymerase high fidelity, and gels were stained with SYBR gold. The RTPCR experiments did not detect toxb mRNA suggesting, that toxb is either not transcribed under these conditions or it is transcribed at levels not detectable by our RT-PCR method (Fig. 4B). Similar results were obtained when these experiments were repeated with fungal tissue grown in continuous darkness (data not shown).

\section{DISCUSSION}

\section{Genomic organization of ToxB.}

Phosphorimage analysis suggests there are approximately nine copies of ToxB in race 5 isolates of $P$. tritici-repentis. Of these nine copies, six copies were cloned and characterized. ToxA and ToxB, both from $P$. tritici-repentis, are currently the only characterized genes that directly encode a HST, and only a single ToxA gene is found in isolates that produce Ptr ToxA. Other characterized HST are products of multienzymatic pathways (Otani et al. 1995; Walton 1996; Wolpert et al. 2002; Yoder et al. 1997). Some of the nonproteinaceous HST have redundant genes, but not to the extent seen with ToxB. Cochliobolus carbonum, for example, has three copies of the fatty acid synthase gene TOXC and two copies of the peptide synthetase gene HTS1 (Ahn and Walton 1997; Panaccione et al. 1992). Both genes are required for the production of HC-toxin (Ahn and Walton 1997; Panaccione et al. 1992). Alternaria alternata f. sp. kikuchiana has multiple copies of several genes involved with the production of AK-toxin (Tanaka and Tsuge 2000; Tanaka et al. 1999); however, gene-knockout experiments suggest that these extra copies are nonfunctional (Tanaka et al. 1999). It is not known if all the ToxB loci are actively tran-
A

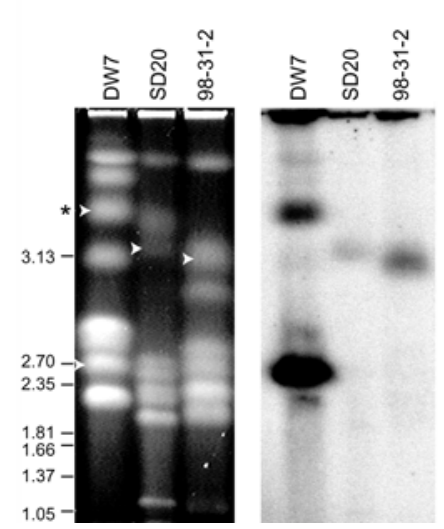

C

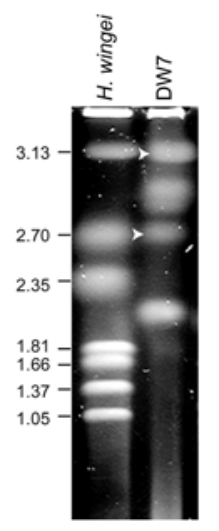

D

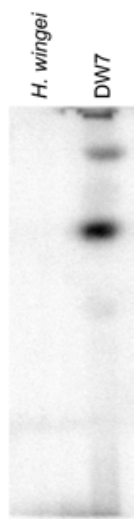

Fig. 3. Identification of chromosomes of Pyrenophora tritici-repentis that contain ToxB and toxb. A, Chromosomes of pathogenic race 5 isolate (DW7) and two nonpathogenic race 4 isolates (SD20 and 98-31-2) resolved by clamped homogenous electric field (CHEF) using method I and stained with SYBR gold. B, Blot of CHEF gel in panel A probed simultaneously with ToxB and toxb. C, Chromosomes of pathogenic race 5 isolate DW7 resolved by CHEF, using method II and stained with SYBR gold. D, Blot of CHEF gel in panel C probed simultaneously with ToxB and toxb. Arrowheads indicate chromosomes that hybridized strongly to the ToxB/toxb probes. Size markers ( $\mathrm{Mb})$ are based on chromosomes of Hansenula wingei. The size of the 3.5-Mb chromosome in isolate DW7, indicated with an asterisk in panel A, was determined on a separate gel (not shown), using method III electrophoretic conditions and a Schizosaccharomyces pombe size standard. scribed or if multiple gene copies result in more transcript, and hence, an increase in disease severity on wheat genotypes that are sensitive to Ptr ToxB. There is some evidence to support this hypothesis. Race 5 isolate $92-171 \mathrm{R} 5$ is significantly less pathogenic, that is, it produces less chlorosis than race 5 isolate $\mathrm{Alg}$ 3-24 (Strelkov et al. 2002). Isolate 92-171R5 was estimated to have two copies of ToxB, whereas Alg 3-24 was estimated to have eight copies (Strelkov et al. 2003). Furthermore, there was less ToxB transcript from isolate 92-171R5 grown in culture compared with that from isolate Alg 3-24, although the differences were not quantitated (Strelkov et al. 2003).

The Southern analysis of CHEF-resolved chromosomes suggests that most of the ToxB loci are located on a single 2.7-Mb chromosome (Fig. 3B and D). It remains to be determined if these genes are clustered or dispersed.

\section{Comparison of the ToxB loci and their flanking regions.}

Of the estimated nine copies of ToxB, all six copies that we analyzed had identical ORFs and, thus, encode the same form of Ptr ToxB. In addition, the first 400 bp upstream of the translational start site and $250 \mathrm{bp}$ downstream of the translational stop site were identical for five of the six loci. This lack of polymorphism in the ToxB ORFs and a portion of the bordering sequence may indicate that the amplification of ToxB was relatively recent; and thus, there has not been sufficient time for genetic variation to accumulate. Although the six ToxB ORFs were identical, there were differences upstream that could affect the transcription of the various copies. Three of the ToxB loci, 2.86 (ToxB1, ToxB2) and $0.93 \mathrm{~kb}$ (ToxB5), have a 197-bp insertion located 425 bp upstream of their ORFs

A
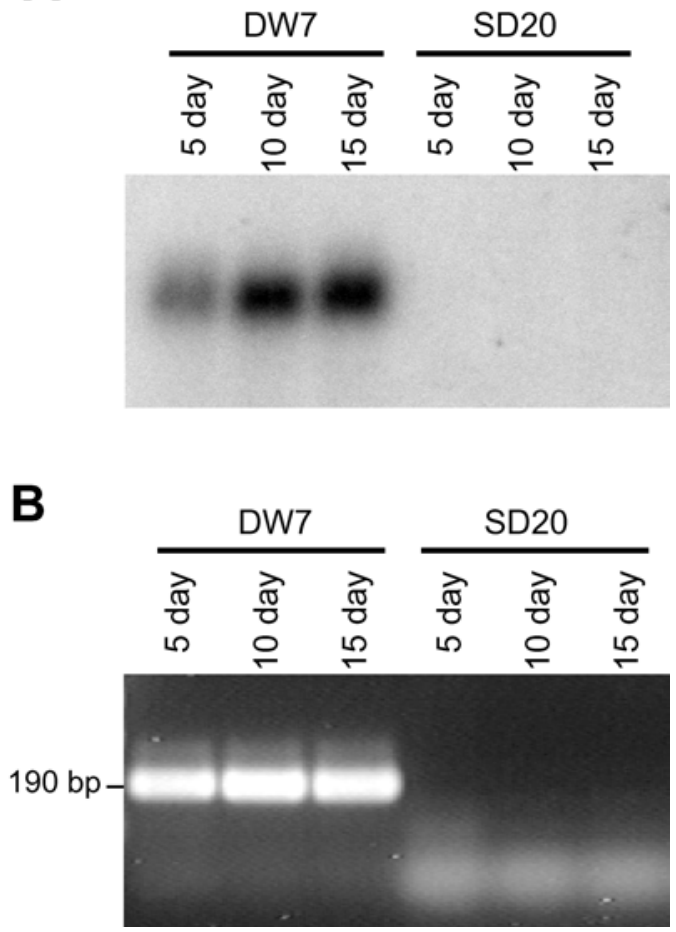

Fig. 4. Nonpathogenic isolate SD20 does not produce a detectable toxb transcript under conditions that favor the expression of ToxB. A, Northern analysis of ToxB expression from a pathogenic race 5 isolate (DW7) and toxb expression from a nonpathogenic race 4 isolate (SD20). Fungal tissue for both isolates was grown in modified Fries medium for 5, 10, and 15 days with constant illumination. Total RNA $(10 \mu \mathrm{g})$ was resolved on an agarose gel, was blotted, and was probed simultaneously with ToxB and toxb. B, Reverse-transcriptase-polymerase chain reaction analysis of cDNA from the same RNA samples used in panel A. 
(Fig. 1B, green box). The location of this insertion may lie within the promoter of ToxB. The ToxB promoter is located $>300$ bp upstream of the ORF, because RT-PCR experiments indicate that the ToxB transcript extends at least $305 \mathrm{bp}$ upstream of the ORF (J. P. Martinez, N. W. Oesch, and L. M. Ciuffetti, unpublished data). Promoter studies with a reporter gene would provide information about the location and strength of the ToxB promoter and the effect of the 197-bp insertion on gene expression.

Tox $B$ has recently been found in races 6,7 , and 8 of $P$. tritici-repentis (Lamari et al. 2003; Strelkov et al. 2002). Strelkov and associates (2003) also reported that race 3 isolate D308 carries the ToxB ORF. However, race 3 isolates do not produce chlorosis on the Ptr ToxB-sensitive cultivar Katepwa (Lamari et al. 2003), suggesting that one or more of these copies of ToxB are poorly expressed. The HindIII restriction-fragment patterns for races 6,7 , and 8 also indicate that ToxB is present in multiple copies in these races (Lamari et al. 2003). However, the restriction-fragment patterns were different among these three races, and except for race 6 , they were different than the four race 5 isolates that we examined. Our visual examination of the ToxB Southern blots of races 6, 7, and 8 from Lamari and associates (2003) also suggests that there are differences in copy number among the races. The polymorphic ToxB restriction patterns between the races and the possible differences in copy number suggest that the Tox $B$ loci are or were in a state of flux. Direct comparisons between race 5 isolates used in this study and races 3, 6, 7, and 8 isolates were not possible because these isolates were unavailable when these experiments were conducted.

All of the ToxB loci were associated with truncated retrotransposon-like sequences (Fig. 1B, red lines). Retrotransposons are one of two classes of mobile elements that are found in all organisms (Berg and Howe 1989). Truncated forms of the original retrotransposon are commonly found in their respective hosts, as was the case for retrotransposon sequences associated with the ToxB loci. The retrotransposon sequences associated with the copies of ToxB could provide the basis for gene amplification or deletion, or both, by unequal crossing over with the same or similar sequences located elsewhere in the genome. Gao and associates (2002) postulated that the copy number diversity of the $T L H$ gene family among $M$. grisea isolates could be explained by unequal crossing over between repetitive elements associated with the $T L H$ gene family.

The 288-bp truncated gypsy-like retrotransposon sequence that is found 400 to $600 \mathrm{bp}$ upstream of most of the ToxB loci (Fig. 1B, red line) may be involved in gene regulation, because of its proximity to the ToxB translational start site. Several mammalian genes are regulated by upstream retroviral sequences (Banville and Boie 1989; Chang-Yeh et al. 1991; Stavenhagen and Robins 1988; Ting et al. 1992). Retrotransposon-like sequences are also expected to regulate several plant genes (White et al. 1994). We were unable to obtain additional 5' sequence for the 1.7-kb locus (ToxB4), so it is not known if this locus also has the 288-bp retrotransposon sequence that is associated with the other cloned loci. This 288-bp retrotransposon sequence was most similar to the retrotransposon Maggy from M. grisea (accession number AAA33420). Maggy-like sequences were also found in a race $1\left(T o x B^{-}\right)$isolate of $P$. tritici-repentis (Lichter et al. 2002). Maggy-like sequences were present on most of the chromosomes of the race 1 isolate. In contrast, only a few chromosomes of the nonpathogenic race 4 isolate hybridized weakly to the Maggy-like probe (Lichter et al. 2002).

\section{Role of toxb in nonpathogenic race 4 isolates.}

Of the characterized genes involved with the synthesis of HST, there is no corresponding allele found in nonpathogenic isolates. Thus, we were intrigued to find a gene (toxb) in nonpathogenic race 4 isolates that shared $86 \%$ similarity to the chlorosis toxin gene, ToxB. None of the six cloned ToxB loci appear to be allelic with the toxb locus. This conclusion is based on the observation that none of the ToxB locus-specific regions were found in the toxb ORF-flanking regions (Fig. 1B legend). The function of toxb in nonpathogenic isolates remains to be determined. If tox $b$ is an active gene, it is regulated differently than ToxB. ToxB transcript was relatively abundant under the tested culture conditions; however, toxb transcript was not detected under these same conditions (Fig. 4). This difference in transcription could be a reflection of the significant sequence differences in the first $750 \mathrm{bp}$ upstream of the two ORFs (Fig. 1B). This region most likely contains all or portions of a transcriptional promoter. In contrast to our results, Strelkov and associates (2003) detected a toxb transcript by RT-PCR in a race 4 isolate. This discrepancy with our data could be explained by differences in the race 4 isolates. Our toxb expression studies involved isolate SD20, and their studies involved isolate 90-2. Alternatively, the contrasting results could be explained by differences in methodology. For example, differences in culture conditions, methods used to synthesize cDNA, or PCR conditions could impact the detection of rare toxb transcript. Race 4 isolates, which contain toxb, are considered to be nonpathogenic. However, this designation is based on inoculations of wheat differentials tested thus far. These "nonpathogenic" race 4 isolates could be pathogenic on an untested wheat genotype or one or more hosts other than wheat. Interestingly, Ali and Francl (2003) reported that race 4 isolates accounted for $98 \%$ of the $P$. tritici-repentis races isolated from noncereal grasses. In contrast, race 4 isolates only composed $5 \%$ of the races isolated from bread wheat. Consequently, investigations of the function of toxb and its putative protein Ptr toxb should include noncereal hosts that are associated with race 4 isolates. Future studies will be directed toward understanding the function of Ptr toxb in nonpathogenic isolates of $P$. tritici-repentis.

\section{MATERIALS AND METHODS}

\section{Fungal isolates.}

The following isolates of $P$. tritici-repentis were used in this study. Race 1 isolate BFP (Tuori et al. 1995) is a subculture derived from isolate Pt-1C obtained from W. Bockus (Kansas State University, Manhattan, U.S.A.). Race 2 isolate 86-124 (Lamari and Bernier 1989) was obtained from L. Francl (Pennsylvania State University, University Park, U.S.A.). Race 4 isolate SD20 was obtained from G. Buchenau (South Dakota State University, Brookings, U.S.A.). The four race 5 isolates (DW2, DW7, DW13, and DW16) were collected from durum wheat fields in North Dakota (Ali et al. 1999) and were provided by L. Francl. Race 9 isolate (Manning et al. 2002) SO3 was collected from a wheat field in southern Oregon (M. L. Putnam and L. M. Ciuffetti, unpublished data).

\section{Cloning and sequencing of ToxB loci and the toxb locus.}

Three subgenomic HindIII libraries were constructed from race 5 isolate DW7. Genomic DNA $(5 \mu \mathrm{g})$ was digested with HindIII, and three fractions (2.5 to $3.1 \mathrm{~kb}, 1.4$ to $1.8 \mathrm{~kb}$, and 0.7 to $1.0 \mathrm{~kb}$ ) were gel-purified with a Qiagen mini column (Valencia, CA, U.S.A.). Each HindIII fraction was ligated with pBS SK+ (Stratagene, La Jolla, CA, U.S.A.), and then, ligated DNA was used to transform ultracompetent XL10-gold E. coli cells (Stratagene). The library was screened using standard methods (Sambrook et al. 1989). ToxB positive clones were not detected in the 1.4 to $1.8 \mathrm{~kb}$ HindIII subgenomic library; therefore, inverse (I)-PCR (Ochman et al. 1988; Triglia et al. 1988) was used to clone the 1.7-kb HindIII locus (ToxB4). 
HindIII-digested genomic DNA (3 $\mathrm{ng} / \mu \mathrm{l})$ from isolate DW7 was self-ligated. Ligated products were then used in a PCR reaction with primers TB4 (GTGGAGGACGTTGTTAGTAA ACAGAG) and TB5 (Table 1). A 1.7-kb I-PCR product was gel-purified and cloned into pGEM-T Easy (Promega, Madison, WI, U.S.A.).

Thermal asymmetric interlaced (TAIL)-PCR (Liu and Whittier 1995; Liu et al. 1995) with DW7 genomic DNA was used to obtain sequence information 5' of the ToxB ORFs. Table 1 describes primers that were used to obtain this additional $5^{\prime}$ sequence. Two TAIL-PCR products, 1.8 and $2.0 \mathrm{~kb}$, were amplified with primers TB3, TB5, TB6, and degenerate primer TP1 and were cloned into the vector pGEM-T Easy. The clones were identical except for a 197-bp insertion in the $2.0-\mathrm{kb}$ clone. To assign the two different 5 ' ends to some or all of the six ToxB HindIII loci, PCR experiments were conducted with a forward primer common to the $5^{\prime}$ end of both TAILPCR products along with a reverse primer specific for a particular locus. For example, primer TB21 (5' end of 1.8- and 2.0-kb TAIL-PCR clones) and primer TB42 (specific for the 2.61-kb HindIII locus ToxB3) produced a 3.9-kb PCR product from DW7 genomic DNA. This PCR product was sequenced and compared with the 2.61-kb HindIII sequence and the two TAIL-PCR products, which allowed assignment of the appropriate 5 ' region to this particular locus. If a particular locusspecific primer did not produce a product with primer TB21, then primers TB22 and TB32 located 3 ' of TB21 were used with a locus-specific primer. This approach allowed additional 5 ' sequence to be assigned for all of the ToxB HindIII loci except for the 1.7-kb HindIII locus (ToxB4).

The ToxB-like locus in isolate SD20 (race 4) is referred to as tox $b$ at this time because this isolate and other race 4 isolates tested thus far are nonpathogenic on wheat genotypes that are sensitive to Ptr ToxB. The toxb locus from nonpathogenic isolate SD20 was amplified from genomic DNA with primers TB10 (TATGCGACCCTAACCTAGCC) and TB12 (GCCAGATAAAAAACCCCTATACC) and cloned into the vector pGEM-T Easy. Additional toxb sequence 3' of TB12 was obtained by TAIL-PCR using primers TB9 (CTACAAGCTCCT GTGGTCTC), TB4 (GTGGAGGACGTTGTTAGTAAACAG AG), and degenerate primer AD2 (AGWGNAGWANCAWA GG). The TAIL-PCR product was cloned into pGEM-T Easy.

To determine if toxb was unique to race 4 isolates, PCR reactions were performed with primer TB7 and toxb-specific primer TB58 (TATGAATGATTGACTGGGGTTA) and 25 to $50 \mathrm{ng}$ of genomic DNA of isolates DW7 and SD20 (positive control). To determine if ToxB was unique to race 5 isolates, PCR reactions were performed with primer TB7 and ToxBspecific primer TB60 (ACTAACAACGTCCTCCACTTTG) and 25 to $50 \mathrm{ng}$ of genomic DNA of isolates SD20 and DW7 (positive control). Conditions for PCR were similar to those described for reverse-transcriptase (RT)-PCR.

DNA was sequenced at the Central Services Laboratory, Center for Gene Research and Biotechnology (CGRB), Oregon State University (Corvallis, OR, U.S.A.), on an ABI Prism 3100 Genetic Analyzer using ABI Prism BigDye terminator cycle sequencing (Applied Biosystems, Foster City, CA, U.S.A.).

\section{Southern analysis.}

Mycelia for genomic DNA extraction were grown in potato dextrose broth. Lyophilized mycelia (100 to $400 \mathrm{mg}$ ) were ground in liquid nitrogen and were added to $7.5 \mathrm{ml}$ of extraction buffer (1\% sodium dodecyl sulfate [SDS], $100 \mathrm{mM}$ $\mathrm{Na}_{2} \mathrm{SO}_{3}, 100 \mathrm{mM}$ Tris, $\mathrm{pH}$ 8.0, 50 mM EDTA). Samples were mixed and incubated at $65^{\circ} \mathrm{C}$ for 15 to $45 \mathrm{~min}$. After the addition of $3.2 \mathrm{ml}$ of $7.5 \mathrm{M} \mathrm{NH}_{4}$ acetate, $9 \mathrm{ml}$ of chloroform were added. Samples were mixed and centrifuged at $10,000 \times g$ for $15 \mathrm{~min}$. Nucleic acids from the aqueous phase were precipitated with 1 volume of isopropanol. Nucleic acids were then resuspended in $500 \mu \mathrm{l} 10 \mathrm{mM}$ Tris $(\mathrm{pH} \mathrm{8.0)}$, and RNA was digested with $20 \mu \mathrm{l}$ RaseA (10 mg/ml). A modification of the method by Michaels and associates (1994) was used to remove most of the polysaccharides. DNA samples were brought to $0.25 \mathrm{M} \mathrm{NaCl}$, and then, an equal volume of $30 \%$ ethanol in $0.14 \mathrm{M} \mathrm{NaCl}$ was slowly added with continuous mixing. Samples were placed on ice for 10 to $20 \mathrm{~min}$ and then were centrifuged at $15,000 \times g$ for $10 \mathrm{~min}$. DNA remaining in the supernatant was precipitated with 0.6 volumes of isopropanol. The DNA pellet was washed with $70 \%$ ethanol and resuspended in $10 \mathrm{mM}$ Tris (pH 8.0).

Approximately $1 \mu \mathrm{g}$ of DNA was digested with HindIII and was resolved on a $1 \%$ agarose gel. DNA was downward transferred onto GeneScreen Plus membranes (Perkin Elmer, Boston). The blot was dried at $80^{\circ} \mathrm{C}$ and was prehybridized for $1 \mathrm{~h}$ at $60^{\circ} \mathrm{C}$ in $7 \%$ SDS, $0.5 \mathrm{M} \mathrm{NaHPO}_{4}$, and $1 \%$ bovine serum albumin. The 186-bp ToxB probe was amplified with primers TB6 and TB7 (Martinez et al. 2001a). Following purification of the ToxB PCR product on a Qiagen mini column, the PCR product was radiolabeled with $\alpha-\mathrm{P}^{32}$-dCTP using the Prime-a-Gene random priming kit (Promega). The ToxB probe was incubated with the blot for at least $16 \mathrm{~h}$ at $60^{\circ} \mathrm{C}$. Following hybridization, the blot was washed at low stringency for 5,10 , and $30 \mathrm{~min}$ at $55^{\circ} \mathrm{C}$ in $2 \times \mathrm{SSC}(1 \times \mathrm{SSC}$ is $0.15 \mathrm{M} \mathrm{NaCl}$ plus $0.015 \mathrm{M}$ sodium citrate), $0.1 \%$ SDS. A Storm PhosphorImager (Amersham, Piscataway, NJ, U.S.A.) located at the CGRB was used to detect DNA fragments that hybridized to the ToxB probe.

\section{Northern analysis and RT-PCR.}

Tissue for RNA extractions was grown as stationary cultures in modified Fries medium (Tomas and Bockus 1987) at $25^{\circ} \mathrm{C}$ in the dark or under constant fluorescent light for 5, 10, and 15 days. RNA was extracted from lyophilized mycelia (30 to 45 mg) with Trizol (Invitrogen, Carlsbad, CA, U.S.A.) according to the manufacturer's instructions, except an extra chloroform extraction was performed. To help remove polysaccharides, RNA was precipitated with $2 \mathrm{M} \mathrm{LiCl}$ for $1 \mathrm{~h}$ at $-20^{\circ} \mathrm{C}$. RNA concentrations were determined using the fluorescent dye RiboGreen (Molecular Probes, Eugene, OR, U.S.A.). Total RNA $(10 \mu \mathrm{g})$ was resolved according to standard methods and was downward transferred onto a Hybond $\mathrm{N}+$ membrane (Amersham) in 10× SSC. Northern blots were hybridized as described above for Southern analysis with a probe containing equal amounts of $T o x B$ and toxb. Following hybridization, blots were washed for 10,10 , and $30 \mathrm{~min}$ at $55^{\circ} \mathrm{C}$ in $2 \times \mathrm{SSC}$, $0.1 \%$ SDS. A phosphorimager was used to detect RNA fragments that hybridized to the ToxB/toxb probes.

For RT-PCR, RNA samples were treated with DNase I as specified by the manufacturer of the DNA-free kit (Ambion, Austin, TX, U.S.A.). cDNA was produced as described by Martinez and associates (2001a), except $2 \mu \mathrm{g}$ of total RNA was used per reaction and oligo-dT primer was removed with a Qiagen MinElute column. RT-PCR reactions $(25 \mu \mathrm{l})$ consisted of $60 \mathrm{mM}$ Tris- $\mathrm{SO}_{4}\left(\mathrm{pH} 8.9\right.$ ), $18 \mathrm{mM} \mathrm{NH}_{4} \mathrm{SO}_{4}, 2 \mathrm{mM} \mathrm{MgSO}$, $0.2 \mathrm{mM}$ dNTP, 0.75 units platinum Taq polymerase high fidelity (Invitrogen), and $0.2 \mu \mathrm{M}$ primer TB7 and TB60 for isolate DW7 or TB7 and TB59 (ACTAACAACGTCCTCCA CTTGC) for isolate SD20. PCR reactions were incubated for 2 $\min$ at $94^{\circ} \mathrm{C}$, followed by 35 cycles of $20 \mathrm{~s}$ at $94^{\circ} \mathrm{C}, 20 \mathrm{~s}$ at $55^{\circ} \mathrm{C}$, and $20 \mathrm{~s}$ at $68^{\circ} \mathrm{C}$, and a final extension of $5 \mathrm{~min}$ at $68^{\circ} \mathrm{C}$. To maximize detection of RT-PCR products, agarose gels were stained with SYBR gold (Molecular Probes). Northern analysis and RT-PCR were performed on two independent sets of fungal cultures. 
Protoplast preparation and pulsed field gel electrophoresis.

The procedure for generating protoplasts was based on previously published methods (Ciuffetti et al. 1997; Zhong et al. 2002). Protoplast solution (3 to $5 \mathrm{ml}$ per g of mycelium) contained $15 \mathrm{mg}$ of Novozyme per ml (InterSpex, San Mateo, CA, U.S.A.), $5 \mathrm{mg}$ of driselase per ml (Sigma, St. Louis), and 1,500 u of $\beta$-glucuronidase per ml (Sigma). For each $\mathrm{ml}$ of protoplast solution, the enzymes were first dissolved in $100 \mu \mathrm{l} 1 \mathrm{M}$ sorbitol before adding $900 \mu \mathrm{l}$ of 1.2 $\mathrm{M} \mathrm{MgSO}_{4}, 10 \mathrm{mM}$ sodium phosphate buffer ( $\mathrm{pH}$ 5.8). Mycelia were incubated in protoplast solution for approximately 3 $\mathrm{h}$ at 25 to $28^{\circ} \mathrm{C}$ with gentle shaking. The protoplast suspension was filtered through $100 \mu \mathrm{m}$ Nitex (Sefar America, Briarcliff Manor, NY, U.S.A.) and was rinsed with $1 \mathrm{M}$ sorbitol. Protoplasts were pelleted by centrifugation at $2,000 \times g$ for $15 \mathrm{~min}$ and were resuspended in $1 \mathrm{M}$ sorbitol. Protoplasts were mixed with molten low melting point agarose (LMA) to achieve $10^{8}$ protoplasts per $\mathrm{ml}$ and $0.8 \%$ LMA. This mixture was then pipetted into plug molds. Protoplast plugs were incubated overnight in NDS buffer $(0.5 \mathrm{M}$ EDTA, $1 \%$ sarkosyl, $10 \mathrm{mM}$ Tris, $\mathrm{pH} 8.0$, and $1 \mathrm{mg}$ of proteinase $\mathrm{K}$ per $\mathrm{ml}$ ).

Chromosome-sized DNA from the protoplast plugs was resolved on 0.8 to $1 \%$ FastLane agarose (FMC, Rockland, ME, U.S.A.) in $1 \times$ Tris-acetate-EDTA buffer at 12 to $14^{\circ} \mathrm{C}$ with a CHEF DRII system (Bio-Rad, Hercules, CA, U.S.A.). Three sets of running conditions were used. Method I was from Lichter and associates (2002) and consisted of a pulse length of 960 to $480 \mathrm{~s}$ over $96 \mathrm{~h}$ and an initial voltage of $75 \mathrm{~V}$ with a $5 \mathrm{~V}$ increase every $24 \mathrm{~h}$. Method II consisted of a pulse length of 720 to $480 \mathrm{~s}$ over $72 \mathrm{~h}$ and an initial voltage of $80 \mathrm{~V}$ with a $5 \mathrm{~V}$ increase every $24 \mathrm{~h}$. Method III was based on a modification from Tooley and Carras (1992) and consisted of a pulse length of 3 to $45 \mathrm{~min}$ at $45 \mathrm{~V}$ for $168 \mathrm{~h}$, with a buffer change after 4 days. Protoplast plugs from Hansenula wingei and Schizosaccharomyces pombe were used as size standards (BioRad). Chromosome-sized DNA was stained with SYBR gold. CHEF gels were depurinated and blotted onto Hybond $\mathrm{N}+$ membranes (Amersham) in $0.4 \mathrm{M} \mathrm{NaOH}$. Blots were probed simultaneously with ToxB and toxb. Following high stringency washes of blots $\left(0.2 \times \mathrm{SSC}, 0.1 \% \mathrm{SDS}, 60^{\circ} \mathrm{C}\right)$, a phosphorimager was used to detect chromosomes that hybridized to the ToxB/toxb probes.

\section{ACKNOWLEDGMENTS}

This research was supported by a National Science Foundation Minority Postdoctoral Research Fellowship to J. P. Martinez (grant number 0109202) and in part by a U.S. Department of Agriculture-NRICGP grant to L. M. Ciuffetti (grant number 01-35319-10017). We thank T. Sweat for assistance with screening the subgenomic libraries for ToxB. We also thank V. A. Manning and R. M. Andrie for helpful comments and suggestions.

\section{LITERATURE CITED}

Ahn, J.-H., and Walton, J. D. 1997. A fatty acid synthase gene in Cochliobolus carbonum required for production of HC-toxin, cyclo(Dprolyl-L-alanyl-D-alanyl-L-2-amino-9,10-epoxi-8-oxodecanoyl). Mol. Plant-Microbe Interact. 10:207-214.

Ali, S., and Francl, L. J. 2002. A new race of Pyrenophora tritici-repentis from Brazil. Plant Dis. 86:1050.

Ali, S., and Francl, L. J. 2003. Population race structure of Pyrenophora tritici-repentis prevalent on wheat and noncereal grasses in the great plains. Plant Dis. 87:418-422.

Ali, S., Francl, L. J., and DeWolf, E. D. 1999. First report of Pyrenophora tritici-repentis race 5 from North America. Plant Dis. 83:591.

Ali, S., Ling, H., Meinhardt, S., and Francl, L. 2002. A new race of Pyrenophora tritici-repentis that produces a putative host-selective toxin. (Abstr.) Phytopathology 92:S3.
Ali, S., Cartwright, R., Friesen, T., Rasmussen, J., and Milus, G. 2003. Novel Pyrenophora tritici-repentis isolates from Arkansas wheat. (Abstr.) Phytopathology 93:S3.

Ballance, G. M., Lamari, L., and Bernier, C. C. 1989. Purification and characterization of a host-selective necrosis toxin from Pyrenophora tritici-repentis. Physiol. Mol. Plant Pathol. 35:203-213.

Ballance, G. M., Lamari, L., Kowatsch, R., and Bernier, C. C. 1996. Cloning, expression and occurrence of the gene encoding the Ptr necrosis toxin from Pyrenophora tritici-repentis. Mol. Plant Pathol. publication/1996/ballance. Published online.

Banville, D., and Boie, Y. 1989. Retroviral long terminal repeat is the promoter of the gene encoding the tumor-associated calcium-binding protein oncomodulin in the rat. J. Mol. Biol. 207:481-490.

Berg, D. E., and Howe, M. M. 1989. Mobile DNA. American Society for Microbiology, Washington, D.C.

Chang-Yeh, A., Mold, D. E., and Huang, R. C. 1991. Identification of a novel murine IAP-promoted placenta-expressed gene. Nucleic Acids Res. 19:3667-3672.

Ciuffetti, L. M., and Tuori, R. P. 1996. Analysis of the ToxA gene of Pyrenophora tritici-repentis, causal agent of tan spot of wheat. (Abstr.) Phytopathology 86:S91.

Ciuffetti, L. M., and Tuori, R. P. 1999. Advances in the characterization of the Pyrenophora tritici-repentis-wheat interaction. Phytopathology 89:444-449.

Ciuffetti, L. M., Tuori, R. P., and Gaventa, J. M. 1997. A single gene encodes a selective toxin causal to the development of tan spot of wheat. Plant Cell 9:135-144.

Ciuffetti, L. M., Francl, L. J., Ballance, G. M., Bockus, W. W., Lamari, L., Meinhardt, S. W., and Rasmussen, J. B. 1998. Standardization of toxin nomenclature in the Pyrenophora tritici-repentis/wheat interaction. Can. J. Plant Pathol. 20:421-424.

DeWolf, E. D., and Francl, L. J. 1998. Empirical infection period models for tan spot of wheat. Can. J. Plant Pathol. 20:394-395.

Effertz, R. J., Meinhardt, S. W., Anderson, J. A., Jordahl, J. G., and Francl, L. J. 2002. Identification of a chlorosis-inducing toxin from Pyrenophora tritici-repentis and the chromosomal location of an insensitivity locus in wheat. Phytopathology 92:527-533.

Gao, W., Khang, C. H., Park, S. Y., Lee, Y. H., and Kang, S. 2002. Evolution and organization of a highly dynamic, subtelomeric helicase gene family in the rice blast fungus Magnaporthe grisea. Genetics 162:103112.

Lamari, L., and Bernier, C. C. 1989. Virulence of isolates of Pyrenophora tritici-repentis on 11 wheat cultivars and cytology of the differential host reactions. Can. J. Plant Pathol. 11:284-290.

Lamari, L., Sayoud, R., Boulif, M., and Bernier, C. C. 1995. Identification of a new race of Pyrenophora tritici-repentis: Implications for the current pathotype classification system. Can. J. Plant Pathol. 17:312-318.

Lamari, L., Strelkov, S., Yahyaoui, A., Orabi, J., and Smith, R. B. 2003. The identification of two new races of Pyrenophora tritici-repentis from the host center of diversity confirms a one-to-one relationship in tan spot of wheat. Phytopathology 93:391-396.

Lichter, A., Gaventa, J. M., and Ciuffetti, L. M. 2002. Chromosome-based molecular characterization of pathogenic and non-pathogenic wheat isolates of Pyrenophora tritici-repentis. Fungal Genet. Biol. 37:180-189.

Liu, Y. G., and Whittier, R. F. 1995. Thermal asymmetric interlaced PCR: Automatable amplification and sequencing of insert end fragments from P1 and YAC clones for chromosome walking. Genomics 25:674681.

Liu, Y. G., Mitsukawa, N., Oosumi, T., and Whittier, R. F. 1995. Efficient isolation and mapping of Arabidopsis thaliana T-DNA insert junctions by thermal asymmetric interlaced PCR. Plant J. 8:457-463.

Manning, V. A., Pandelova, I., and Ciuffetti, L. M. 2002. A race for a novel host-selective toxin. (Abstr.) Phytopathology 92:S51.

Martinez, J. P., Ottum, S. A., Ali, S., Francl, L. J., and Ciuffetti, L. M. 2001a. Characterization of the ToxB gene from Pyrenophora triticirepentis. Mol. Plant-Microbe Interact. 14:675-677.

Martinez, J. P., Ottum, S. A., and Ciuffetti, L. M. 2001b. Characterization of the ToxB gene from Pyrenophora tritici-repentis. Abstr. Page 113 in: 21st Fungal Genetics Conference. Pacific Grove, CA, U.S.A.

Martinez, J. P., Oesch, N. W., and Ciuffetti, L. M. 2002. Analysis of the multiple copy host-selective toxin gene, ToxB, from Pyrenophora tritici-repentis. (Abstr.) Phytopathology 92:S52.

Michaels, S. D., Manorama, C. J., and Amasino, R. M. 1994. Removal of polysaccharides from plant DNA by ethanol precipitation. BioTechniques 17:274-276.

Nielsen, H., Engelbrecht, J., Brunak, S., and von Heijne, G. 1997. Identification of prokaryotic and eukaryotic signal peptides and prediction of their cleavage sites. Protein Eng. 10:1-6.

Ochman, H., Gerber, A. S., and Hartl, D. L. 1988. Genetic applications of an inverse polymerase chain reaction. Genetics 120:621-623. 
Orolaza, N. P., Lamari, L., and Ballance, G. M. 1995. Evidence of a hostspecific chlorosis toxin from Pyrenophora tritici-repentis, the causal agent of tan spot of wheat. Phytopathology 85:1282-1287.

Otani, H., Kohmoto, K., and Kodama, M. 1995. Alternaria toxins and their effects on host plants. Can. J. Bot. 73:S453-S458.

Panaccione, D. G., Scott-Craig, J. S., Pocard, J. A., and Walton, J. D. 1992. A cyclic peptide synthetase gene required for pathogenicity of the fungus Cochliobolus carbonum on maize. Proc. Natl. Acad. Sci. U.S.A. 89:6590-6594.

Sambrook, J., Fritsch, E. F., and Maniatis, T. 1989. Molecular Cloning: A Laboratory Manual, 2nd ed. Cold Spring Harbor, NY, U.S.A.

Sigrist, C. J., Cerutti, L., Hulo, N., Gattiker, A., Falquet, L., Pagni, M., Bairoch, A., and Bucher, P. 2002. PROSITE: A documented database using patterns and profiles as motif descriptors. Brief Bioinform. 3:265-274.

Stavenhagen, J. B., and Robins, D. M. 1988. An ancient provirus has imposed androgen regulation on the adjacent mouse sex-limited protein gene. Cell 55:247-254.

Strelkov, S. E., Lamari, L., and Ballance, G. M. 1999. Characterization of a host-specific protein toxin (Ptr ToxB) from Pyrenophora tritici-repentis. Mol. Plant-Microbe Interact. 12:728-732.

Strelkov, S. E., Lamari, L., Sayoud, R., and Smith, R. B. 2002. Comparative virulence of chlorosis-inducing races of Pyrenophora tritici-repentis. Can. J. Plant Pathol. 24:29-35.

Strelkov, S. E., Kowatsch, R. F., Ballance, G. M., and Lamari, L. 2003. Occurrence and expression of ToxB in races of Pyrenophora triticirepentis. Pages 15-18 in: Proceedings from the Fourth International Wheat Tan Spot and Spot Blotch Workshop. J. B. Rasmussen, T. L. Friesen, and S. Ali, eds. North Dakota Extension Service, ND, U.S.A.

Tanaka, A., and Tsuge, T. 2000. Structural and functional complexity of the genomic region controlling AK-toxin biosynthesis and pathogenicity in the Japanese pear pathotype of Alternaria alternata. Mol. PlantMicrobe Interact. 13:975-986.

Tanaka, A., Shiotani, H., Yamamoto, M., and Tsuge, T. 1999. Insertional mutagenesis and cloning of the genes required for biosynthesis of the host-specific AK-toxin in the Japanese pear pathotype of Alternaria alternata. Mol. Plant-Microbe Interact. 12:691-702.

Tatiana, A. T., and Madden, T. L. 1999. Blast 2 sequences-a new tool for comparing protein and nucleotide sequences. FEMS (Fed. Eur. Microbiol. Soc.) Lett. 174:247-250.
Ting, C. N., Rosenberg, M. P., Snow, C. M., Samuelson, L. C., and Meisler, M. H. 1992. Endogenous retroviral sequences are required for tissue-specific expression of a human salivary amylase gene. Genes Dev. 6:1457-1465.

Tomas, A., and Bockus, W. W. 1987. Cultivar-specific toxicity of culture filtrates of Pyrenophora tritici-repentis. Phytopathology 77:13371340

Tomas, A., Feng, G. H., Reeck, G. R., Bockus, W. W., and Leach, J. E. 1990. Purification of a cultivar-specific toxin from Pyrenophora triticirepentis, causal agent of tan spot of wheat. Mol. Plant-Microbe Interact. 3:221-224.

Tooley, P. W., and Carras, M. M. 1992. Separation of chromosomes of Phytophthora species using CHEF gel electrophoresis. Exp. Mycol. 16:188-196.

Triglia, T., Peterson, M. G., and Kemp, D. J. 1988. A procedure for in vitro amplification of DNA segments that lie outside the boundaries of known sequences. Nucleic Acids Res. 16:8186.

Tuori, R. P., Wolpert, T. J., and Ciuffetti, L. M. 1995. Purification and immunological characterization of toxic components from cultures of Pyrenophora tritici-repentis. Mol. Plant-Microbe Interact. 8:41-48.

Walton, J. D. 1996. Host-selective toxins: Agents of compatibility. Plant Cell 8:1723-1733.

White, S. E., Habera, L. F., and Wessler, S. R. 1994. Retrotransposons in the flanking regions of normal plant genes: A role for copia-like elements in the evolution of gene structure and expression. Proc. Natl. Acad. Sci. U.S.A. 91:11792-11796.

Wolpert, T. J., Dunkle, L. D., and Ciuffetti, L. M. 2002. Host-selective toxins and avirulence determinants: What's in a name? Annu. Rev. Phytopathol. 40:251-285

Yoder, O. C., Macko, V., Wolpert, T. J., and Turgeon, B. G. 1997. Cochliobolus spp. and their host-specific toxins. Pages 145-166 in: The Mycota, Vol. 5: Plant Relationships, Part A. G. Carroll and P. Tudzynski, eds. Springer-Verlag, Berlin.

Zhang, H. F., Francl, L. J., Jordahl, J. G., and Meinhardt, S. W. 1997. Structural and physical properties of a necrosis-inducing toxin from Pyrenophora tritici-repentis. Phytopathology 87:154-160.

Zhong, S., Steffenson, B. J., Martinez, J. P., and Ciuffetti, L. M. 2002. A molecular genetic map and electrophoretic karyotype of the plant pathogenic fungus Cochliobolus sativus. Mol. Plant-Microbe Interact. 15:481-492. 